The Egyptian Journal of Hospital Medicine (January 2019) Vol. 74 (2), Page 460-466

\title{
Evaluation of Diagnostic Laparoscopy with laparoscopic Appendectomy in Females with Acute Right Lower Quadrant Pain, a Multicenter Study
}

\author{
Nesreen Aref ${ }^{1}$, Mohamed Al Saeed ${ }^{2}$, Bilal O Al-Jiffry ${ }^{2}$, Majed Al-Mourgi ${ }^{2}$, Alaa Younes ${ }^{2}$, Tamer \\ Abdel-Rahman ${ }^{2,3}$, Samir Badr ${ }^{2,4}$, Abdullah Al-Sawat ${ }^{2}$ \\ ${ }^{1}$ Department of Obstetrics and Gynecology, Taif University, Saudi Arabia, ${ }^{2}$ Department of Surgery, Taif \\ University, Saudi Arabia , ${ }^{3}$ General Organization of Teaching Hospitals and Institutes (Benha), ${ }^{4}$ General \\ Organization of Teaching Hospitals and Institutes (Damanhur)
}

\begin{abstract} operative or early postoperative mortality was recorded. incidental appendectomy

\section{Introduction:}

Appendicitis is the most common cause of cute right lower quadrant abdominal pain (ARLQP); however, a broad spectrum of common and uncommon conditions may mimic acute appendicitis especially in women of childbearing age which may carry a diagnostic dilemma ${ }^{[1-}$ 3]. Accurate diagnosis is the cornerstone in avoiding inappropriate treatment and despite improvements in imaging; it may still be difficult to differentiate between gynecologic and nongynecologic causes of abdominal pain which makes diagnostic laparoscopy to be the gold standard for proper diagnosis and treatment in
\end{abstract}

Background and aim of the study: Diagnostic laparoscopy is the gold standard for diagnosis of acute right lower abdominal pain (ARLQP) in females especially in child bearing age and its value to perform laparoscopic appendectomy in such complex conditions is gaining acceptance amongst surgeons. The aim of this multicenter study was to evaluate the values of diagnostic laparoscopy with laparoscopic appendectomy in female patients with acute right lower quadrant abdominal pain.

Material and method: This multicenter prospective study enrolled 253 female patients who presented with acute right lower quadrant pain to Taif tertiary hospitals (Saudi Arabia) and performed laparoscopic appendectomy during diagnostic laparoscopy from May 2012 to April 2017.

Results: The study included 253females with mean age of 31.1 66.8 years. Diagnostic laparoscopy with laparoscopic appendectomy was done for all of them. Acute appendicitis was the most common cause of ARLQP (22.1\%). 10.5\% of macroscopically normal appendices had acute appendicitis. Mean total operating time was $65.6 \pm 14.7$ and for the appendectomy portion of the operation it was $14.3 \pm 2.8$ minutes when the appendix was grossly inflamed and it was $11.8 \pm 2.3$ minutes when the appendix was apparently normal (incidental appendectomy). The mean hospital stay for grossly inflamed appendix was $24.8 \pm 5.5$ hours, of incidental appendectomy without associated pelvic pathology was $22.3 \pm 5.2$ hours increased to $72.4 \pm 16.5$ hours if other pelvic pathology was managed. Post operative complications occurred in $4 \%$. No

Conclusion: This study supports the value of diagnostic laparoscopy in diagnosis and management of females with ARLQP and verified that acute appendicitis is the most common cause in such females. The study proved also that laparoscopic appendectomy is safe, effective, quick in addition; the study verified the role of incidental appendectomy in prevention of reoperation for future appendicitis.

Keywords: Females, Lower abdominal pain, diagnostic laparoscopy, laparoscopic appendectomy,

such condition ${ }^{[4]}$.Diagnostic laparoscopy may reduce the need for unnecessary open appendectomy; however, it does not prevent missed acute appendicitis as some studies found that about one third of normally appearing appendices was inflamed on pathological review even in presence of other pelvic pathology ${ }^{[5,6]}$. Most of the studies found that laparoscopic appendectomy has less postoperative pain, a shorter hospital stay, and fewer complications than conventional approach ${ }^{[7-14]}$.Incidental appendectomy which is the removal of a macroscopically normal appendix has been 
evolved during diagnostic laparoscopyespeciallyin females with ARLQP ${ }^{[7]}$. The procedure gained popularity amongst surgeons to avoid future acute appendicitis and the need of recurrent hospitalization and reoperation ${ }^{[7-14]}$. The aim of this multicenter study was to evaluate the values of diagnostic laparoscopy with incidental appendectomy in female patients with acute right lower quadrant abdominal pain.

Materials and method: This multicenter prospective study was conducted in Taif tertiary hospitals from May 2012 to April 2017. The study was conducted after approval of the ethical committees of the hospitals and taking informed written consents from the patients. The study enrolled 253 female patients who presented with acute right lower quadrant pain and performed appendectomy during diagnostic laparoscopy. All patients underwent diagnostic laparoscopy to confirm preoperative diagnosis and manage the underlying cause. In all cases appendectomy were done either it was grossly inflamed or not and sent for pathological examination with any other resected or biopsied pathological lesion. The operating time of the incidental appendectomy was calculated in addition to the total operative time. The primary outcome was the pathological findings of the removed appendices and secondary outcomes included intraoperative findings, operating time, hospital stay, postoperative morbidity and mortality. Cases of appendicular masses, abscess, inflammatory conditions of the cecum involving the base of the appendix, ileocecal tumors, and any condition indicated laparotomy were excluded from the study.

Full history and complete physical examination were done for all patients. Further workup included pregnancy test, urine analysis, complete blood count, plain abdominal x-rays, pelviabdominal ultrasound or/and CT scanning. All patients received general endotracheal anaesthesia, operated in supine position (modified to Trendelenburg position in some cases), in the majority of cases (184/253 "72.7 $\% "$ the open laparoscopy technique was used to introduce the umbilical port and in the other cases Veress needle laparoscopic approach was used. In all cases pneumoperitoneum with $\mathrm{CO} 2$ was established to a pressure of $15 \mathrm{mmHg}$. A $10 \mathrm{~mm}$ $0^{\circ}$ laparoscope was introduced through the umbilical port and was connected to a video camera. After a short diagnostic exploration for the abdomen and pelvis, two or three 5-mm ancillary trocars were placed in the abdomen. Two were placed in the right and left lower quadrants (the left one was not used by some surgeons) and the third was placed approximately 1-2 inches above the symphysis pubis. The entire abdomen and pelvis ere thoroughly inspected with a blunt-tipped probe and the operative findings were recorded. The primary pathology was dealt with first including the removal of grossly inflamed appendix; however, if the appendix was appearing normal, incidental appendectomy was performed at the end of the procedure. Variable equipments were used to deal with the pathological findings and to remove the appendix and included; graspers, forceps, scissors, bipolar and monopolar cautery, LigaSure, laparoscopic sutures and pre-knotted loops, clips, and staplers.

Otherwise a major procedure was performed patients were discharged within 24 hours to be followed up after one week in the outpatient clinic and instructed to attend the emergency department at any time if they encountered an unresolved problem.

Statistical analysis: Data were collected, coded and tabulated. Statistical analysis was performed using SPSS program version 20.5 (SPSS Inc., Chicago, IL, USA).Descriptive statistics were done and quantitative data were expressed as number, percentage, and mean \pm standard deviation.

Results: The study included 253females with mean age of $31.1 \pm 6.8$ years. Diagnostic laparoscopy with incidental appendectomy was done for all of them. Table 1 shows the pathological lesions found in the patients and that acute appendicitis was the most common cause of ARLQP; however, acute appendicitis was associated with other pelvic pathology in 18/253 of cases $(7.1 \%)$. Appendectomy was done in 253 patients, 33 of them had a grossly inflamed appendices and proved by histopathological examination. Twenty three appendices of 220 incidentally removed appendices were proved to be inflamed on pathological examination $(10.5 \%)$.Acute appendicitis was clinically 
diagnosed in 67/253 of patients with ARLQP and only $42 / 67$ cases $(62.7 \%)$ were proved pathologically $(37.3 \%$ had false positive diagnosis). Fourteen of 253 patients $(5.5 \%)$ were not preoperatively diagnosed as acute appendicitis and were proved on pathological examination to be inflamed. Table 2 shows different pathological lesions associating acute appendicitis. Mean operating time for appendectomy was $14.3 \pm 2.8$ minutes when the appendix was grossly inflamed and it was $11.8 \pm 2.3$ minutes when the appendix was apparently normal and the total operating time

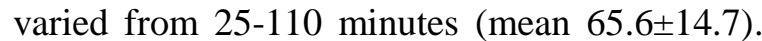
The mean hospital stay for grossly inflamed appendix was $24.8 \pm 5.5$ hors, of incidental appendectomy without associated pelvic pathology was $22.3 \pm 5.2$ hours increased to $72.4 \pm 16.5$ hours if other pelvic pathology was managed. Postoperative complications occurred in 10/253 patients (4\%) and included; 9 cases of post operative fever and the causes were; cellulitis around the port skin incision in 3 cases, urinary tract infection in 3 cases, and superficial thrombophlebitis in 2 cases and all were treated conservatively in addition tone patient developed pelvic collection which was treated by ultrasound guided drainage, and the last complication was bleeding due to injury of omental vessel during introduction of the trocar and was treated laparoscopically after resuscitation. No operative or early postoperative mortality was recorded. Figure 1 shows macroscopically inflamed appendix, Figure 2 shows appendix removed by stapler, Figure 3 shows use of LigaSure to divide the mesoappendix, and Figure 4 shows appendectomy of macroscopically normal appendix

Table 1: Pathological findings in the studied patients

\begin{tabular}{|c|c|}
\hline Pathologically proved acute appendicitis & $56 / 253(22.1 \%)$ \\
\hline \multirow{2}{*}{$\begin{array}{l}\text { Grossly inflamed } \\
\text { Apparently normal and proved to be appendicitis }\end{array}$} & $33 / 253(13 \%)$ \\
\hline & $23 / 253(9.1 \%)$ \\
\hline Other pathologies & $197 / 253(77.9 \%)$ \\
\hline _ Ruptured ovarian cyst & $49 / 253(19.4 \%)$ \\
\hline - PID & $31 / 253(12.3 \%)$ \\
\hline - $\quad$ Endometriosis & $25 / 253(9.9 \%)$ \\
\hline Para adenexa adhesions & $24 / 253(9.5 \%)$ \\
\hline Torsion of ovarian cyst & $18 / 253(7.1 \%)$ \\
\hline Ectopic pregnancy & $15 / 253(5.9 \%)$ \\
\hline - $\quad$ Mittel Schmerz & $14 / 253(5.5 \%)$ \\
\hline - Ileocolitis & $14 / 253(5.5 \%)$ \\
\hline Ileocecal crohn's disease & $7 / 253(2.8 \%)$ \\
\hline Meckel's diverticulitis & $5 / 253(2 \%)$ \\
\hline - Omental infarction & $2 / 253(0.8 \%)$ \\
\hline Non-identified cause & $2 / 253(0.8 \%)$ \\
\hline
\end{tabular}

Table 2: Association of acute appendicitis with other pelvic pathology

\begin{tabular}{|c|c|}
\hline Total number of acute appendicitis (\%) & $56 / 253(22.1)$ \\
\hline Acute appendicitis with no other pathology (\%) & $38 / 253(15 \%)$ \\
\hline Acute appendicitis and other pelvic pathology (\%) & $18 / 253(7.1 \%)$ \\
\hline Adhesion $(\%)$ & $11 / 253(4.3 \%)$ \\
\hline PID $(\%)$ & $5 / 253(2 \%)$ \\
\hline Endometriosis (\%) & $1 / 253(0.4 \%)$ \\
\hline Inflamed Meckel's(\%) & $1 / 253(0.4 \%)$ \\
\hline
\end{tabular}




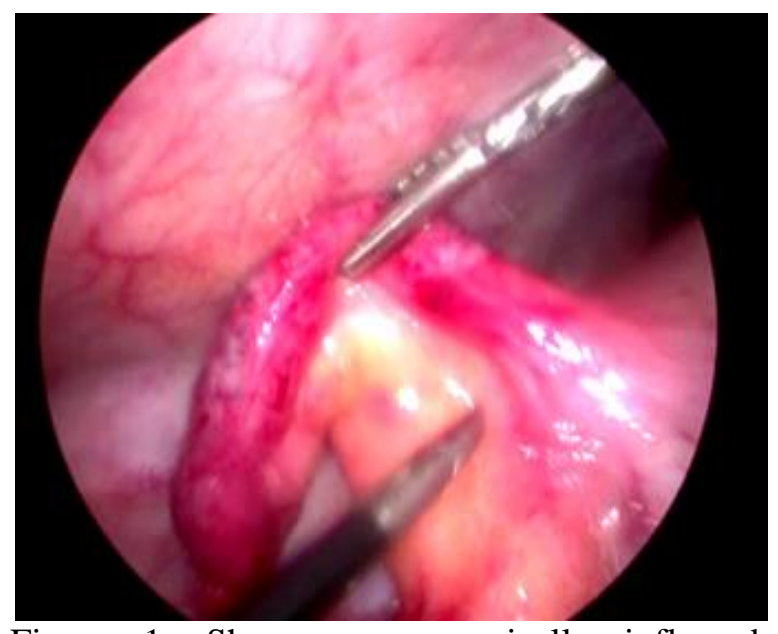

Figure 1: Shows macroscopically inflamed appendix

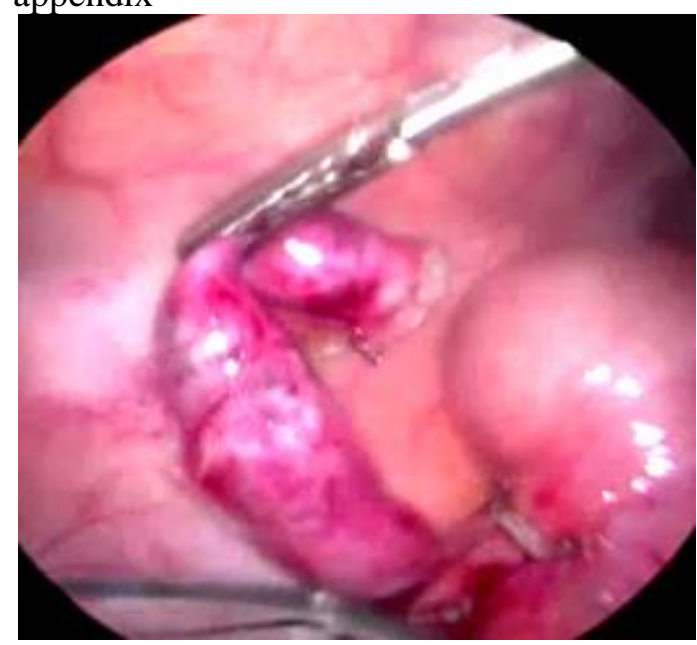

Figure 2: Appendix removed by stapler

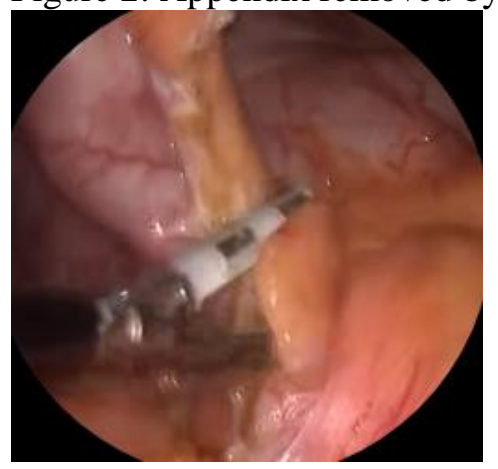

Figure 3: Use of LigaSure to divide the mesoappendix

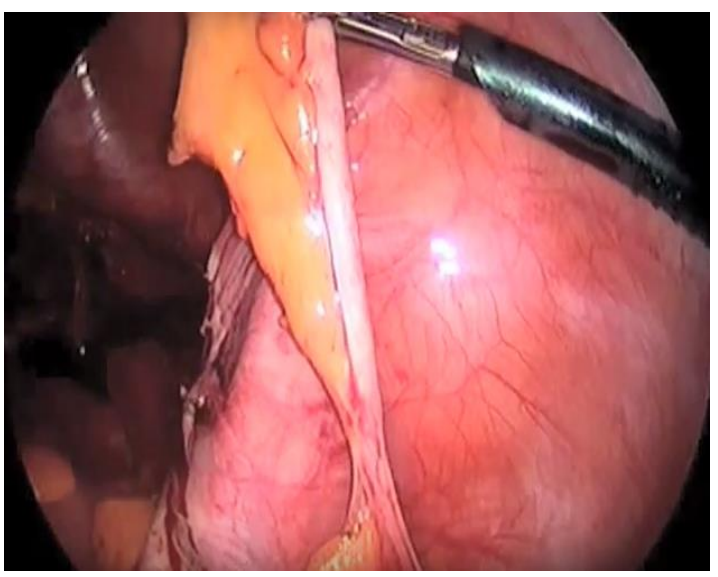

Figure 4: appendectomy of macroscopically normal appendix

\section{Discussion}

Acute appendicitis is the most common surgical emergency especially in patients presenting with ARLQP ${ }^{[1-3]}$. A wide differential diagnosis should be kept in mind when faced with a woman of childbearing age with abdominal pain, so,Consensus European Association of Endoscopic Surgeons (EAES) guidelines have emphasized the value of routine diagnostic laparoscopy as an efficient tool in such females ${ }^{[2]}$. Morino et al. in their study found that acute appendicitis was the cause of ARLQP pain in $18 \%$ of cases and gynecological causes in $15 \%$ only of cases; however, the study of Anteby et al. found that appendicitis was the cause of pelvic pain in 3\% only of cases and gynecological pathologies represented $57 \%$ of cases ${ }^{[16,17]}$.In the present study acute appendicitis was encountered in $22.1 \%$ of representing the most common pathology in females with ARLQP; however, double pathology was met in $7.1 \%$. This difference in the results of different studies may be related to the sample size and the difference in patient selection to perform diagnostic laparoscopy.

Previous studies found that over $40 \%$ of patients operated upon for suspected acute appendicitis had macroscopically normal appendices and as the accepted standard of care in such conditions is to remove the normal appearing appendix to avoid future appendicitis, however, the reported morbidity of this ranges from $11-17 \%^{[5-6]}$. With the advance in technology,diagnostic laparoscopy has been evolved which improved the diagnostic accuracy with a reduction in the 
Evaluation of Diagnostic Laparoscopy with laparoscopic Appendectomy in Females...

normal appendectomy rate ${ }^{[15]}$. In the study of Ragland et al. diagnostic laparoscopy reduced negative appendectomy rate from $42 \%$ to $15 \%$ and the diagnostic accuracy was $100 \%$ in predicting the exact cause of $\mathrm{ARLQP}^{[18]}$. In the present study the preoperative diagnosis of acute appendicitis had its drawbacks where the false positive diagnosis was $37.3 \%$; however, diagnostic laparoscopy assisted to reach the diagnosis in over $99 \%$ of cases of ARLQP and the cause was not identified in less than $1 \%$ of cases.Diagnostic laparoscopy increased diagnostic accuracy without elimination of the problem of missed appendicitis where its rate was $9-29 \%$ in various studies ${ }^{[7-14]}$. Song et al. in their study confirmed appendicitis pathologically in $4.3 \%$ only of the incidentally removed appendices; however, they found that only $22.7 \%$ of the appendices in 772 cases enrolled in their study were normal; the rest had varying degrees of pathology and the most common pathology result was adhesions, followed by fibrosis ${ }^{[19]}$.In the present study about one third (18/56) of all cases of pathologically proved acute appendicitis (grossly inflamed or incidentally removed) were associated with other pelvic pathology which supports the concept of removal of normally appearing appendix as part of management of ARLQP even in presence of other pathology.

Phillips et $\boldsymbol{a l}$. found in their study that correct intraoperative diagnosis of acute appendicitis was achieved in $84 \%$ of cases and $29 \%$ of the macroscopically normal appendices had appendicitis on pathological diagnosis and they concluded that laparoscopy is a good tool for the diagnosis of acute right iliac fossa pain, management of pelvic pathological lesions including laparoscopic appendectomy of the grossly inflamed appendix and advocated removal of a normally appearing appendix to avoid future appendicitis [20]. In our study laparoscopic appendectomy was performed in all cases and more than ten per cent of incidentally removed normally appearing appendices had acute appendicitis upon pathological examination which supports the findings in the previous studies. Based on these findings investigators accepted that the use of laparoscopy should not alter the sound surgical judgment to remove the normal appendix when operating for acute right lower quadrant abdominal pain which supported the value of incidental appendectomy in prevention of future appendicitis and reoperation ${ }^{[19,20]}$.Song et al. emphasized in their study that women with an initial diagnosis of appendicitis were more likely than women without this diagnosis to have appendicitis on pathology examination after incidental appendectomy ${ }^{[19]}$.

In accordance with the findings in our study, investigators found that the total operating time of laparoscopic appendectomy is longer than the conventional approach (ranged between 55-72 minutes vs. 30-45 minutes) even with highly experienced surgeons and this is related to additional steps like setup of instruments, insufflation, inserting ports under vision and a phase of diagnostic laparoscopy, and dealing with other pelvic pathology ${ }^{[20]}$.Song et al. in their study calculated every portion of the operation and found that the mean operating time for the incidental appendectomy was $12.3 \pm 4.5$ minutes and the length of the procedure reflected anatomical position of the appendix and the severity of the pelvic pathology ${ }^{[19]}$. In the present study the mean operating time for incidental appendectomy was similar to recorded time in the previous study and the total operating time was in accordance to that of other studies.

Several studies verified that operative morbidity or length of hospitalization were not significantly increased if laparoscopic appendectomy was performed with diagnostic laparoscopy as compared to that of diagnostic laparoscopy alone ${ }^{[7-14,19]}$. The postoperative complication rate in our study was $4 \%$ which was lower than that recorded by most of the other studies (range 5$10 \%$ ); however, Song et al. reported complication rate less than $1 \%$ in their study $[7,9,11,19]$.

The length of hospital stay in the present study was in agreement with several studies and this important factor influences the economy, the patient well-being, and early return to daily activities ${ }^{[7-14,19-25]}$.

Conclusion: This study supports the value of diagnostic laparoscopy in diagnosis and management of females with ARLQP and verified that acute appendicitis is the most common cause in such females. The study proved also that laparoscopic appendectomy is safe, effective, quick in addition; the study verified the 
role of incidental appendectomy in prevention of reoperation for future appendicitis.

\section{References}

1. Paulson EK, Kalady MF, Pappas TN (2003): Clinical practice. Suspected appendicitis. The New England journal of medicine, 348:236-42.

2. Humes DJ, Simpson J (2011): Clinical presentation of acute appendicitis: clinical signs - laboratory findings - clinical scores, Alvarado score and derivative scores. In: Keyzer C, Gevenois PA, editors. Imaging of acute appendicitis in adults and children. Springer-Verlag.

3. Andersson RE (2004): Meta-analysis of the clinical and laboratory diagnosis of appendicitis. The British journal of surgery, 91:28-37.

4. Khatuja R, Jain G, Mehta S, Arora N, Juneja A, Goel N (2014): Changing Trends in Use of Laparoscopy: A Clinical Audit. Minimally Invasive Surgery, 562785.

5. Andrew MH and Roty AR J (1987): Incidental appendectomy with cholecystectomy: Is the increased risk justified?. Am Surg., 53:553.

6. Chang FC, Hogle HH and Welling DR (1973): The fate of the negative appendix. Am J Surg., 126:752.

7. Biondi A, Di Stefano C, Ferrara F, Bellia A, Vacante M, Piazza L (2016):Laparoscopic versus open appendectomy: a retrospective cohort study assessing outcomes and costeffectiveness. World Journal of Emergency Surgery: WJES, 1: 44.

8. Kaderli R (2014): Incidental appendectomy: standard or unjustified risk? Ther Umsch., 71: 753-8.

9. Frazee R, Burlew CC, Regner J, McIntyre R, Peltz E, Cribari C et al. (2017): Outpatient laparoscopic appendectomy can be successfully performed for uncomplicated appendicitis: A Southwestern Surgical Congress Multicenter Trial. Am J Surg., 214:1007-9.

10. Alfa-Wali M, Osaghae S (2017): Practice, training and safety of laparoscopic surgery in low and middle-income countries. World Journal of Gastrointestinal Surgery, 9: 13-18.
11. Flum DA, Morris A, Koepsell T, Dellinger EP (2001): Has misdiagnosis of appendicitis decreased over time? JAMA. , 286: 48-53.

12. Flum DA, Koepsell T (2002): The clinical and economic correlates of misdiagnosed appendicitis. Arch Surg., 137:799-804.

13. Sporn E, Petroski GF, Mancini GJ, Astudillo JA, Miedema BW, Thaler K (2009): Laparoscopic appendectomy-is it worth the cost? Trend analysis in the US from 2000 to 2005. J Am Coll Surg., 208: 179-85.

14. Thorell A, Grondal S, Schedvins K, Wallin G (1999): Value of diagnostic laparoscopy in fertile women with suspected appendicitis. The European journal of surgery $=$ Acta chirurgica, 165:751-4.

15. Gorter R, Eker H, Gorter-Stam M, Abis GSA, Acharya A, Ankersmit $\mathrm{M}$ et al. (2016): Diagnosis and management of acute appendicitis. EAES consensus development conference 2015. Surgical Endoscopy, 30: 4668-90.

16. Morino M, Pellegrino L, Castagna E, Farinella E, Mao P (2006): Acute nonspecific abdominal pain: A randomized, controlled trial comparing early laparoscopy versus clinical observation. Ann Surg., 244: 881-8

17. Anteby SO, Schenker JG, Polishuk WZ (1975): The value of laparoscopy in acute pelvic pain. Ann Surg., 181: 484-6.

18. Ragland J, de la Garza J, McKenney J (1988) : Peritoneoscopy for the diagnosis of acute appendicitis in females of reproductive age. Surg Endosc., 2: 36-8.

19. Song J Y, Yordan E, \& Rotman, C (2009): Incidental Appendectomy During Endoscopic Surgery. JSLS : Journal of the Society of Laparoendoscopic Surgeons, 13: 376-83.

20. Phillips AW, Jones AE, Sargen K (2009): Should the macroscopically normal appendix be removed during laparoscopy for acute right iliac fossa pain when no other explanatory pathology is found?. Surg Laparosc Endosc Percutan Tech., 19: 392-4.

21. Cox MR, McCall JL, Wilson TG, Padury R.T.A., Jeans PL, Toouli J (1993): Laparoscopic appendectomy: a prospective analysis. Aust NZ J Surg., 63:840-3. 
22. Al-Temimi MH, Berglin MA, Kim EG, Tessier DJ, Johna SD (2017): Endostapler versus Hem-O-Lok clip to secure the appendiceal stump and mesoappendix during laparoscopic appendectomy. Am J Surg., 214: 1143-8.
23. Hori T, Machimoto T, Kadokawa Y, Hata T, Ito T, Kato S et al. (2017): Laparoscopic appendectomy for acute appendicitis: How to discourage surgeons using inadequate therapy. World Journal of Gastroenterology, 23: 5849-59.

24. Shore EM, Lefebvre GG, Husslein H, Bjerrum F, Sorensen JL, Grantcharov TP (2015): Designing a Standardized Laparoscopy Curriculum for Gynecology Residents: A Delphi Approach. Journal of Graduate Medical Education, 7: 197-202.

25. Itskowitz MS, Jones SM (2004): Appendicitis. Emerg Med., 36:10-15. 